\title{
Can A Sudden Sensorineural Hearing Loss Occur Due to Miliary Tuberculosis?
}

\author{
Sang-Ki Min, Ji-Ho Shin, and Seog-Kyun Mun \\ Department of Otorhinolaryngology-Head and Neck Surgery, Chung-Ang University Hospital, Seoul, Korea
}

$\begin{array}{ll}\text { Received } & \text { May 29, 2017 } \\ \text { Revised } & \text { July 23, 2017 } \\ \text { Accepted } & \text { July 26, 2017 }\end{array}$

Address for correspondence

Seog-Kyun Mun, MD

Department of Otorhinolaryngology-

Head and Neck Surgery,

Chung-Ang University Hospital,

102 Heukseok-ro, Dongjak-gu,

Seoul 06973, Korea

Tel +82-2-6299-1765

Fax +82-2-825-1765

E-mail entdoctor@cau.ac.kr
Miliary tuberculosis is a severe form of tuberculosis resulting from dissemination of Mycobacterium tuberculosis bacilli. Since symptoms appearing in patients due to miliary TB are diverse and atypical, depending on the site of invasion, early diagnosis and treatment are important. A paradoxical response of tuberculosis is a rare phenomenon and it can be a clinical difficulty to treatment especially when involving the central nervous system. We present a case report with a review of related literature about the patient who developed sudden hearing loss due to tuberculosis infection in vestibulocochlear area.

J Audiol Otol 2018;22(1):45-47

KEY WORDS: Tuberculosis · Miliary · Paradoxical reaction · Sudden hearing loss.

\section{Introduction}

Miliary tuberculosis (TB) is a form of tuberculosis characterized by a wide dissemination through vessels or lymph nodes [1]. Since symptoms appearing in patients due to miliary TB are diverse and atypical, depending on the site of invasion, early diagnosis and treatment are important [2]. The most dangerous form involves the central nervous system; if treatment is delayed, permanent neurological changes can occur $[2,3]$. We present a case report with a review of related literature about the patient who developed sudden hearing loss during miliary TB treatment.

\section{Case Report}

There is no conflicts of interest or financial interests in this work. All procedures performed in studies involving human participants were in accordance with the ethical standards of the institutional and/or national research committee and with the 1964 Helsinki declaration and its later amendments or

This is an Open Access article distributed under the terms of the Creative Commons Attribution Non-Commercial License (http://creativecommons.org/licenses/by-nc/4.0/) which permits unrestricted non-commercial use, distribution, and reproduction in any medium, provided the original work is properly cited. comparable ethical standards. We have obtained written informed consent to publish from the participant to report individual patient data.

A 47-year-old male presented to the pulmonology outpatient clinic for the cough that had lasted for two months. At that time, he complained of general weakness, dyspnea and sweating as well as a weight loss of $10 \mathrm{~kg}$ that occurred over a four-month period. There was no specific past history but crackles in the right lung were evident in the physical examination. Numerous disseminated nodules in both lung fields were found in a chest $\mathrm{x}$-ray. Chest computed tomography (CT) revealed a variety of small disseminated nodules in both lungs and mediastinal lymph node. Sputum was tested on suspicion of miliary TB. Test for Mycobacterium tuberculosis (M. tuberculosis) complex was positive. He was admitted into an isolation ward and treated with empirical anti-TB agents (isoniazid $400 \mathrm{mg}$, ethambutol 1,200 mg, rifampicin $600 \mathrm{mg}$ ).

In the seventh day after admission, he complained of the sudden hearing loss and tinnitus in his right ear that had begun that morning. He was referred to Otorhinolaryngology (ENT) consultation for diagnosis and treatment. In addition to a decrease in hearing, there were no other neurological symptoms and vestibular symptoms. Pure-tone audiometry was normal in the left ear, while both bone and air conduction thresh- 
old in the right ear were unresponsive (Fig. 1A). Unilateral sensorineural hearing loss was evident. Other hearing evaluations such as auditory brainstem response, otoacoustic emission did not proceed. Brain T1-weighted axial magnetic resonance imaging revealed multiple nodules $1-4 \mathrm{~mm}$ in size with high signal intensity randomly distributed around the cerebral subcortex, pons, and cerebellum (Fig. 2A). T1-weighted coronal images showed high signal distributed by vestibu- locochlear area and some parts of semicircular canal area (Fig. 2B). According to radiologic findings, we diagnosed the patient as miliary TB with brain and labyrinth invasion. Pyrazinamide was added along with existing anti-TB agents and high-dose steroid therapy (10-day course prednisone 60 mg with taper) was started. Two months later, the multiple nodules were no longer found in the brain CT (Fig. 2C). AntiTB agents were maintained for 12 months. However, both
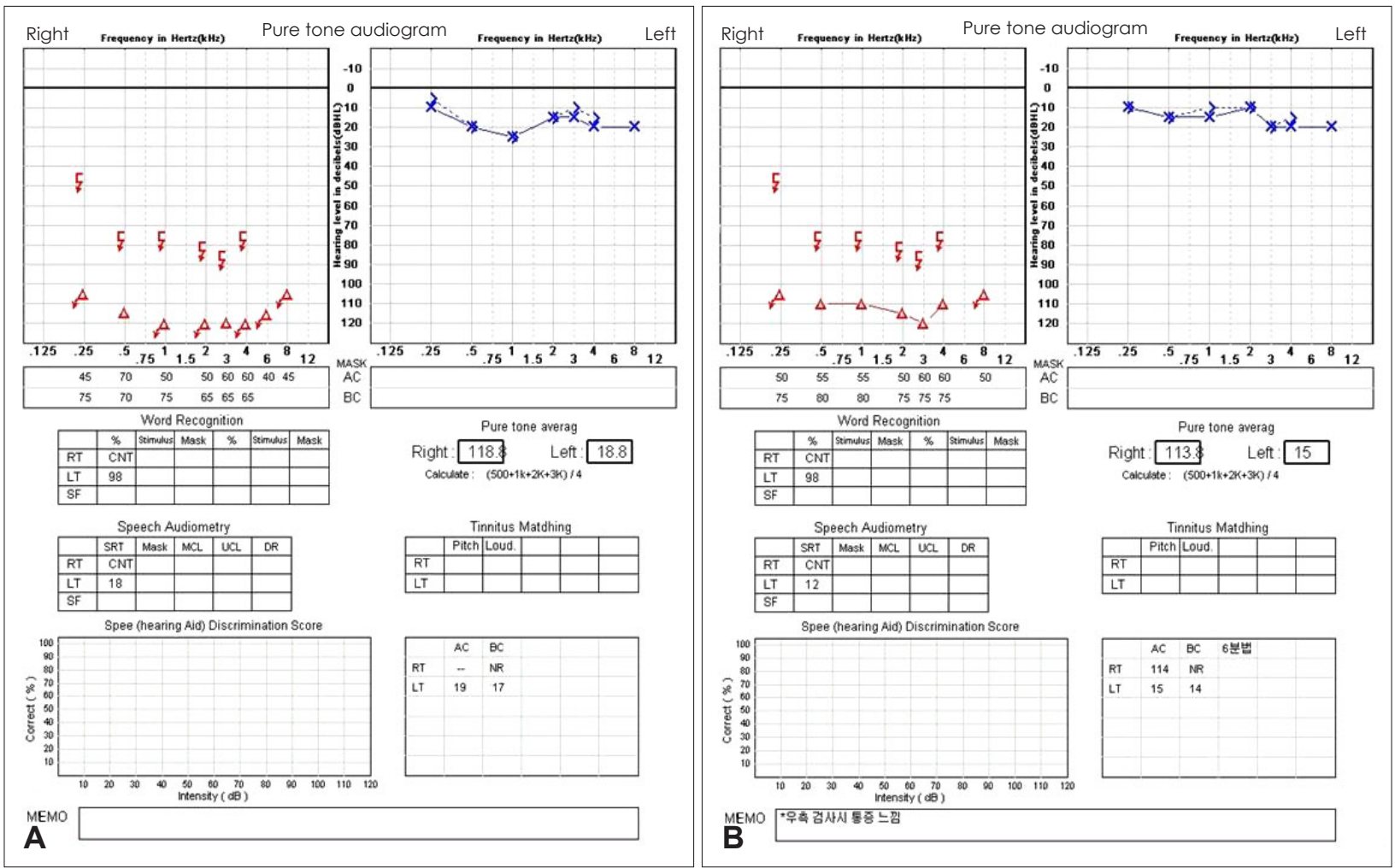

Fig. 1. A: Pure tone audiometry shows the right deafness on the day symptom developed. B: There is no interval change after 6 months later.
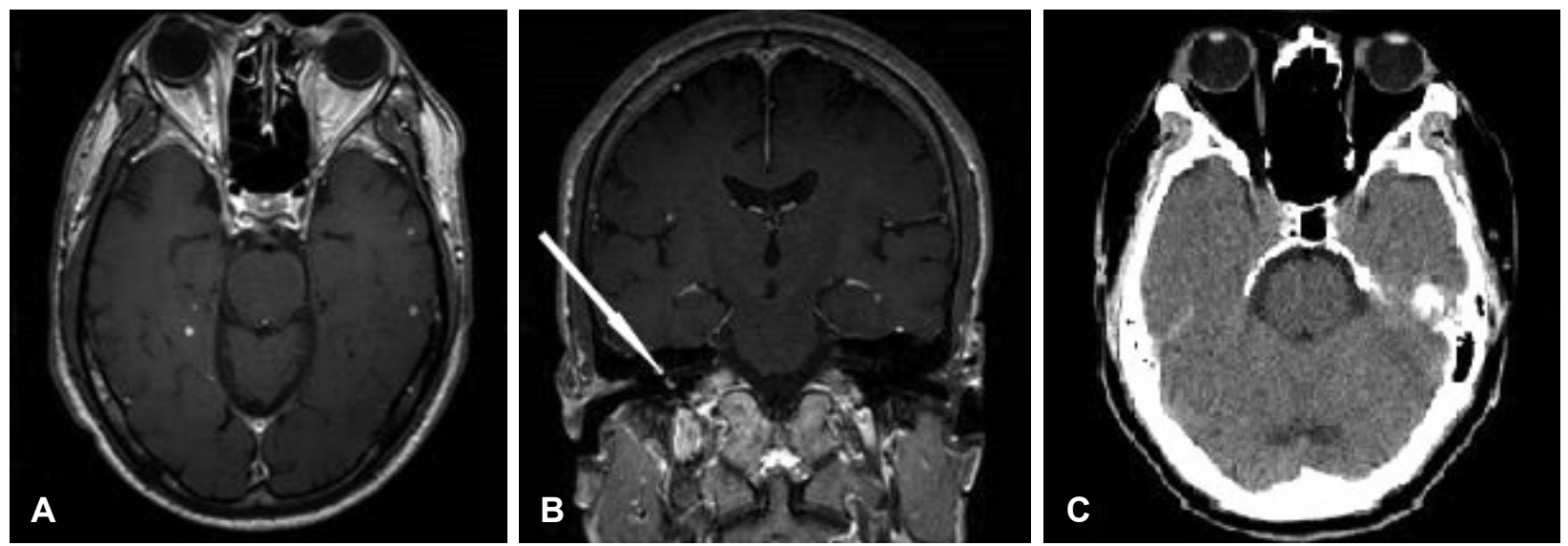

Fig. 2. A: T1-weighted axial view of brain MRI following gadolinium enhancement shows multiple enhancing nodules $4 \mathrm{~mm}$ or less in size with a random distribution in the whole brain parenchyma. B: T1-weighted coronal view with gadolinium enhancement shows enhancing nodule in right vestibule (arrow). C: There are no abnormalities in brain CT scan images taken 2 months after the treat-ment. CT: computed tomography. 
bone and air conduction threshold in the right ear was not improved (Fig. 1B).

\section{Discussion}

Miliary TB due to M. tuberculosis spreads through the blood vessels or lymph nodules forming millet seed-like shaped lesions. The infection accounts for about $1-2 \%$ of all TB cases [1]. The typical form of disseminated chest radiographs and histopathological evidence from clinical symptoms consistent with TB diagnosis, response to anti-TB agents are used as the basis for diagnosis [4]. Miliary TB can occur in all organs including tuberculous meningitis, pleurisy, peritonitis, joint tuberculosis, tuberculous lymphadenitis, and kidney TB and tuberculous meningitis is the most common [5]. Clinical manifestations vary according to the infected organs $[4,5]$.

As in this case, the initial lesion was improved during the treatment, but the new extra lesions developed, worsening the symptoms. This is called as the paradoxical reaction [6]. The mechanism of the paradoxical reaction is unclear [6]. The most convincing theory is related to enhanced immune reaction of the host. Suppression of the patient's immune system can be lessened by TB treatment and antigen released from the cell wall of lysed mycobacteria evokes a hypersensitivity reaction [6,7]. For immunologically isolated central nervous system, microglia, the major antigen-presenting cell, is not capable of presenting antigen [7]. Thus, normally M. tuberculosis does not trigger an immune reaction because they are secluded from the blood-brain barrier. Once they are recognized by the immune system outside of central nervous system they can form intracranial lesions [7]. This paradoxical reaction occurs in $25 \%$ of patients with pulmonary TB and lymph nodes, with the central nervous system most commonly affected [6]. In this case we found disseminated multiple lesions with high signal intensity in vestibulocochlear organs including the cerebrum parenchyma and cerebellum. It is thought that $M$. tuberculosis affects the brain parenchymal and vestibulocochlear area during treatment.

In case of TB that invades the central nervous system, Isoniazid, ethambutol, rifampin and additional pyrazinamide is recommended for 18 to 24 months. Additional pyrazinamide helps to reach the same drug concentration level in blood and cerebrospinal fluid [8]. Based on the immunologic theory that adrenocortical hormones can reduce the risk of neurologic damages after treatment and intracranial pressure, adrenocortical hormones are added [7].

Considering there was no effect on corticosteroid drugs in this case, it is regarded that changes of lymph circulation due to $M$. tuberculosis invasion damaged hair cells. It is assumed that $M$. tuberculosis reached vestibulocochlear area blocking the flow of exo-lymph through the spinal fluid rather than blood vessels. Nitric oxide, produced by macrophage, causes lipid metabolism disorder in the cell membrane and it eventually leads to impairment in intracellular signaling [9,10]. It affects function of inner ear hair cell and makes irreversible changes by deactivation of protein kinase $\mathrm{C}$ [9].

In conclusion, it should be noted that the possibility of central nervous system lesions due to paradoxical response in miliary TB treatment. We report the case of a patient suffering from sudden sensory neural hearing loss in invasion of vestibulocochlear lesions. Thus, when managing patient with TB, it is necessary to conduct proper treatment if atypical neurologic symptoms occurs.

\section{Conflicts of interest}

The authors have no financial conflicts of interest.

\section{REFERENCES}

1) Sharma SK, Mohan A, Sharma A, Mitra DK. Miliary tuberculosis: new insights into an old disease. Lancet Infect Dis 2005;5:415-30.

2) Sonmez G, Ozturk E, Sildiroglu HO, Mutlu H, Cuce F, Senol MG, et al. MRI findings of intracranial tuberculomas. Clin Imaging 2008; 32:88-92.

3) Garg RK. Tuberculosis of the central nervous system. Postgrad Med J 1999;75:133-40.

4) Sharma SK, Mohan A, Pande JN, Prasad KL, Gupta AK, Khilnani GC. Clinical profile, laboratory characteristics and outcome in miliary tuberculosis. QJM 1995;88:29-37.

5) Park JB, Han SH, Kim KN, Lee SY. A case report of miliary tuberculosis diagnosed by chest computer tomography in FUO. J Korean Acad Fam Med 2004;25:397-402.

6) Afghani B, Lieberman JM. Paradoxical enlargement or development of intracranial tuberculomas during therapy: case report and review. Clin Infect Dis 1994;19:1092-9.

7) Park KY, Lee HJ, Jung JW, Choi YH, Nam SB, Ahn SH, et al. A case of different response miliary lung and intracranial nodules to antituberculous therapy. Tuberc Respir Dis 2008;64:153-7.

8) Ceylan E, Gencer M. Miliary tuberculosis associated with multiple intracranial tuberculomas. Tohoku J Exp Med 2005;205:367-70.

9) Barlow DW, Duckert LG, Kreig CS, Gates GA. Ototoxicity of topical otomicrobial agents. Acta Otolaryngol 1995;115:231-5.

10) Lee SH, Kalinec F. Measurement of the mechanical deformation of Organ of Corti in model of acute endolymphatic hydrops. Korean J Otorhinolaryngol-Head Neck Surg 2016;59:110-9. 